\title{
Supplier Capacity and Intermediary Profits: Can Less Be More?
}

\author{
Elodie Adida \\ Operations and Supply Chain Management, School of Business Administration, University of California at Riverside, 225 Anderson Hall, \\ 900 University Ave., Riverside, California, 92521, USA, elodie.goodman@ucr.edu \\ Nitin Bakshi, Victor DeMiguel \\ Management Science and Operations, London Business School, Regent's Park, London, NW1 4SA, UK, \\ nbakshi@london.edu, avmiguel@london.edu
}

\begin{abstract}
W e identify market conditions under which intermediaries can thrive in retailer-driven supply chains. Our main finding is that, as a consequence of the retailers' leadership position, intermediaries prefer products for which the supply base (existing production capacity) is neither too narrow nor too broad; that is, less existing capacity can result in more intermediary profit. We also show that our main finding is robust to (i) the presence of horizontal competition among retailers and intermediaries, (ii) the existence of exclusive suppliers, and (iii) the ability of the retailers to source directly from the suppliers. Nevertheless, we find that horizontal competition between intermediaries encourages them to carry products with relatively smaller production capacity, whereas exclusive suppliers and direct sourcing encourage intermediaries to carry products with relatively larger installed capacity.
\end{abstract}

Key words: intermediation; supply chain; vertical and horizontal competition; Stackelberg leader History: Received: May 2014; Accepted: July 2015 by Haresh Gurnani, after 2 revisions.

\section{Introduction}

For several decades, retailers in developed countries have been sourcing products from low-cost international suppliers. For commodity-type products, which tend to have long life cycles, the retailer's in-house procurement department often establishes a longterm relationship with one or more suitable suppliers. For specialized products such as fashion apparel, fashion shoes, toys, and housewares, however, retailers typically rely on intermediaries. These industries are characterized by high frequency of new product introduction coupled with short product life cycles, and thus require the use of a large and complex network of low-cost international suppliers. Under these circumstances, retailers generally find it economical to outsource the maintenance of this network to intermediaries with deep knowledge of the product market and international supplier base (Ha-Brookshire and Dyer 2008).

A characteristic feature of these supply chains with intermediaries is that the retailers lead the interaction. For instance, fashion retailers continually monitor market trends and generate orders as a response to these rapidly changing trends. Depending on the specific order, the intermediary thereafter selects the suppliers with the technical capability and spare capacity to fulfill demand. In other words, intermediaries orchestrate retailer-driven supply chains as a response to a specific order from a retailer facing incidental demand; see Knowledge@Wharton (2007). Chronologically, the retailer order precedes the orchestration of the supply chain, and thus it makes sense to portray the retailers as leaders.

Trade through intermediaries in retailer-driven supply chains plays an important role in sourcing. Hence, it is important to sharpen our understanding of the determinants of intermediary performance (Peng and York 2001): namely, the industry's competitive structure, and the demand and supply characteristics. In particular, the supply side warrants careful scrutiny because of the well-documented fluctuations in available production capacity (Barrie 2013, Zhao 2013), which in turn affect the economic well-being of intermediaries and other supply chain participants.

Under which market conditions can intermediaries thrive in retailer-driven supply chains? This is our main research question, and to answer it, we consider a three-tier model with one leading retailer, one intermediary, and many suppliers. We characterize the intermediary profit in closed form. Our main finding pertains to the supply side; we find that the 
intermediary profit is unimodal with respect to the number of suppliers in its base. This is in direct contrast with the insight from existing models of serial supply chains, in which suppliers lead (e.g., Corbett and Karmarkar 2001). Based on the literature, one might expect that the larger the supplier base, the larger the market power of the intermediary and thus the larger the intermediary profit. This intuition does bear out when the size of the supplier base is "small." However, in a world where retailers lead, when the supplier base is "large enough," we show that the weakness of the suppliers becomes the weakness of the intermediary, and the retailer exploits its leadership position to increase its market power and retain greater supply chain profits. A crucial implication of this result is that intermediaries in retailer-driven supply chains prefer products for which the supplier base (existing production capacity) is neither too narrow nor too broad, because (ceteris paribus) products that have an intermediate production capacity generate larger intermediary profits.

We also study how our main finding is affected by three realistic extensions: (i) horizontal competition among retailers and intermediaries, (ii) the presence of exclusive suppliers, and (iii) the ability of the retailers to source directly from the suppliers. We study the impact of horizontal competition by increasing the number of retailers and intermediaries, and find that our main insight that intermediary profits are unimodal in the number of suppliers continues to hold even with competing retailers and intermediaries. We find, however, that the number of suppliers that maximizes intermediary profits decreases with the number of intermediaries. The reason for this is that when the number of intermediaries is large, and thus competition among them is stronger, the intermediaries benefit from carrying products with a relatively more inelastic supply side, because this improves their bargaining position with respect to the leading retailers.

To study the impact of exclusive suppliers on our main finding, we consider an extension where every intermediary works with an arbitrary subset of the existing suppliers. This general model captures situations where intermediaries have exclusive as well as shared suppliers, and situations where some intermediaries may be large, and others small. We find that our main finding is robust to the presence of asymmetric intermediaries. Nevertheless, we find that the presence of exclusive suppliers dampens the intensity of competition among intermediaries, and thus the number of suppliers needed to maximize intermediary profits in this situation is larger.

Finally, we consider an extension of our model where the retailer has the option to deal directly with the suppliers (without the intervention of the intermediary) provided he is willing to pay a fixed transaction cost per supplier. We observe that our main finding continues to hold, but the threat of the retailer sourcing directly from suppliers may induce the intermediary to carry products with a relatively larger supply base. Intuitively, the intermediary is willing to give up some of its margin to keep the retailer's business.

Our results have operational implications for intermediation firms. Specifically, a crucial challenge facing intermediaries in retailer-driven supply chains is how to manage their product portfolio in order to maximize their profit. Hsing (1999, Footnote 4), for instance, argues that the ability of Taiwanese fashion shoe manufacturers to maintain a diversified product portfolio was key to their success in the 1980s. Our work suggests that when managing their product portfolio, intermediaries must take into account the variations in the balance between product demand and supplier capacity. In the life cycle of a particular product, the intermediate levels of capacity that maximize intermediary profits will likely arise in the growth and decline phases. Hence, intermediaries with greater flexibility to add and drop products from their portfolio are likely to fare better. This is particularly important in industries such as fashion retail, fashion shoes, and consumer electronics, which exhibit high frequency of new product introduction and short product life cycles. Moreover, our framework enables us to precisely specify this intermediate level of capacity, and to show how it depends on various supply-chain attributes such as the concentration in the intermediary and retailer tiers; the extent of asymmetry between intermediaries; and the ability of retailers to bypass intermediaries.

\section{Relation to the Literature}

We now discuss how our work is related to the literature on intermediation and supply chain competition.

\subsection{Literature on Intermediation}

Our work is related to the Economics literature on intermediation, which according to Wu (2004) "studies the economic agents who coordinate and arbitrage transactions in between a group of suppliers and customers." As mentioned before, the main distinguishing feature of our work is that while the Economics literature has focused on justifying the existence of middlemen through their ability to reduce transaction costs (Biglaiser 1993, Rubinstein and Wolinsky 1987), we focus on understanding the market conditions under which intermediaries can thrive in a retailerdriven supply chain. Our modeling framework differs substantially from the modeling frameworks used in this literature. The intermediation literature generally assumes that each buyer and seller is interested in a single unit for which they have idiosyncratic 
valuations, and price is determined through bilateral bargaining. In contrast, in order to capture the key features of sourcing arrangements, we assume that the interaction between various players is governed by a market mechanism. Accordingly, we model a consumer demand function, as well as quantity competition a la Cournot-Stackelberg. Thus, we are able to track not only the intermediary margin but also the overall efficiency of the supply chain. In summary, our model is closer to the multi-tier competition models developed in recent Operations Management literature, and our focus is on the operational aspects of supply-chain sourcing.

While the above differences make a direct comparison of results difficult, similar to us, Rubinstein and Wolinsky (1987) find that intermediaries make a net profit in equilibrium. However, they are not able to recover any qualitative insight on how intermediary profits depend on the number of sellers. Our main result is that intermediary profit is unimodal in number of suppliers (sellers). Thus, we are able to offer some guidelines on how an intermediary might constitute his product portfolio.

Our work is also related to Belavina and Girotra (2012), who study intermediation in a supply chain with two suppliers, one intermediary, and two buyers, with players in the same tier not competing directly. They provide a new rationale for the existence of intermediaries. Specifically, they show that in a multi-period setting the intermediary is more effective in inducing efficient decisions from the suppliers (e.g., quality related), because the intermediary has access to the pooled demand of both buyers, and therefore superior ability to commit to future business with each supplier. Babich and Yang (2014) consider a supply chain with one retailer, one intermediary, and two suppliers. They consider the case where the suppliers possess private information about their reliability and costs, and they justify the existence of the intermediary because of the informational benefits it offers to the retailer. Again, the main difference between both of these papers and our work is that they focus on explaining the existence of an intermediary tier, while we focus on understanding the market conditions under which intermediaries can thrive in a retailer-driven supply chain.

\subsection{Literature on Supply Chain Competition}

In contrast to our manuscript, most existing models of multi-tier supply-chain competition assume the retailers are followers. A prominent example is Corbett and Karmarkar (2001), herein C\&K, who consider entry in a multi-tier supply chain with vertical competition across tiers and horizontal quantity-competition within each tier. $C \& K$ assume that retailers face a deterministic linear demand function, and that they are followers with respect to the suppliers who face constant marginal costs. Several papers consider variants of the multi-tier supply chain proposed by C\&K with retailers as followers: Carr and Karmarkar (2005), Adida and DeMiguel (2011), Federgruen and $\mathrm{Hu}$ (2013), and Cho (2014). Other Studies consider models in which a single supplier leads several competing retailers: Bernstein and Federgruen (2005), Netessine and Zhang (2005), and Cachon and Lariviere (2005).

Very few papers in the existing literature model the retailers as leaders. For example, Choi (1991) considers a model in which one retailer leads two suppliers. This model assumes that the suppliers possess complete information about the demand function facing the retailer, and that they exploit this information strategically when making their production decisions. This assumption imposes a level of sophistication on the suppliers' strategic capabilities, and endows them with a degree of information that does not seem appropriate for the context of low-cost international suppliers interacting with procurement firms. Moreover, we show in Appendix D of Data S1 that the equilibrium in Choi's model with the retailer as leader is equivalent to that of the model by $C \& \mathrm{~K}$, where the retailers are followers: that is, the equilibrium quantity, retail price, and supply chain aggregate profits are identical for both models. Overall, we think that assuming suppliers can strategically exploit their complete knowledge of the retailers' demand function is not realistic in our setting. This is crucial, because as we demonstrate in this study, incorporating a more apt model for suppliers, along with viewing retailers as leaders, results in substantially different insights than those suggested by the existing literature on supply chain competition.

Majumder and Srinivasan (2008), herein M\&S, consider a model where any of the firms in a network supply chain could be the leader, and study the effect of leadership on supply chain efficiency as well as the effect of competition between network supply chains. M\&S assume increasing marginal cost of manufacturing, and they argue that, "with wholesale price contracts, this is the only assumption that results in equilibrium when suppliers follow."

Our model combines elements from the models of $C \& K$ and $M \& S$ and is tailored to the context of intermediation in retailer-driven supply chains.

\section{When Do Intermediaries Thrive}

To understand how the number of suppliers (or equivalently, the availability of supply capacity) affects the profitability of intermediaries, we first consider a three-tier supply chain, where one retailer leads one intermediary who sources from $S$ suppliers. We find that intermediary profits are unimodal in the 
number of suppliers; that is, intermediaries prefer products for which the existing production capacity is neither too narrow nor too broad.

\subsection{Model}

We model a three-tier supply chain, where the first tier consists of a single retailer who faces the consumer demand captured by a linear demand function. The retailer acts as Stackelberg leader with respect to the intermediary. Specifically, the retailer chooses its order quantity in order to maximize its profit, while anticipating the reaction of the intermediary. The second tier consists of a single intermediary who acts as Stackelberg leader with respect to the suppliers; that is, the intermediary chooses its order quantity in order to maximize its profit, while anticipating the reaction of the suppliers. The third tier consists of $S$ capacity-constrained suppliers who choose their production quantities in order to maximize their profits. In the remainder of this section, we first describe in detail the decision problem at each of the three tiers, and then briefly discuss some of the model features.

3.1.1. Supplier Tier. Given a supplier price $p_{s}$, the $j$ th supplier chooses its production quantity $q_{s, j}$ to maximize its profit:

$$
\max _{q_{s, j}} \quad \pi_{s, j}=p_{s} q_{s, j}-c\left(q_{s, j}\right),
$$

where $p_{s} q_{s, j}$ is the supplier's revenue from sales, and $c\left(q_{s, j}\right)$ is the production cost. Like M\&S, we assume the production cost is convex quadratic: $c\left(q_{s, j}\right)=s_{1} q_{s, j}+\left(s_{2} / 2\right) q_{s, j}^{2}$, or equivalently that the $j$ th supplier has linearly increasing marginal cost:

$$
c^{\prime}\left(q_{s, j}\right)=s_{1}+s_{2} q_{s, j},
$$

where $s_{1}>0$ is the intercept, and $s_{2} \geq 0$ is the sensitivity.

We define the aggregate supply function as the total quantity produced by the suppliers for a given supplier price $p_{s}$. The following result follows from the fact that the $j$ th supplier optimally chooses to produce the quantity such that its marginal cost equals the supply price; that is, the quantity $q_{s, j}$ such that $p_{s}=s_{1}+s_{2} q_{s, j}$.

LeMma 1. For the case with symmetric suppliers, the aggregate supply function is

$$
Q_{s}\left(p_{s}\right)=S q_{s, j}=S\left(p_{s}-s_{1}\right) / s_{2} .
$$

REMARK 1. Note that the suppliers' best response is completely characterized by the aggregate supply function given in Equation (2). There are two implications from this. First, our analysis also applies to the case when suppliers are asymmetric in the cost of production, provided that their aggregate supply function is approximately linearly increasing, or (equivalently) that their aggregate marginal cost function is approximately linearly increasing. ${ }^{1}$ Second, because the aggregate supply function depends on the number of suppliers and their sensitivity only through the ratio $S / s_{2}$, the impact on the equilibrium of an increase in the number of suppliers $S$ is equivalent to the impact of a certain decrease in the supply sensitivity $s_{2}$. Essentially, in our model, the ratio $S / s_{2}$ provides a measure of the total production capacity in the supply chain.

3.1.2. Intermediary Tier. Given an intermediary price $p_{i}$, the intermediary chooses its order quantity $q_{i}$ to maximize its profit, anticipating the reaction of the suppliers as well as the supplier-market-clearing price. The intermediary decision may be written as:

$$
\begin{array}{cl}
\max _{q_{i}, p_{s}} & \pi_{i}=\left(p_{i}-p_{s}\right) q_{i} \\
\text { s.t. } & q_{i}=Q_{s}\left(p_{s}\right),
\end{array}
$$

where $Q_{s}\left(p_{s}\right)$ is the aggregate supply function and Constraint (4) is the supplier-market-clearing condition. We denote the intermediary equilibrium quantity for an intermediary price as $q_{i}\left(p_{i}\right)$.

3.1.3. Retailer Tier. To simplify the exposition, we model demand with a deterministic demand function, although we show in Appendix C of Data S1 that our results generally hold for the case with a stochastic demand function as well. Concretely, we model demand with the following linear inverse demand function $^{2}$ :

$$
p_{r}=d_{1}-d_{2} q,
$$

where $d_{1}$ is the demand intercept and $d_{2}$ is the demand sensitivity.

Assumption 1. We assume throughout the paper that $d_{1}>s_{1}$.

This assumption ensures that the retail price exceeds the marginal cost of the first unit produced by suppliers, so that there is a potential for profits and nonzero quantities.

The retailer chooses its order quantity $q_{r}$ to maximize its profit, anticipating the intermediary reaction and the intermediary-market-clearing price $p_{i}$ :

$$
\begin{gathered}
\max _{q_{r}, p_{i}} \quad \pi_{r}=\left(d_{1}-d_{2} q_{r}-p_{i}\right) q_{r} \\
\text { s.t. } \quad q_{r}=q_{i}\left(p_{i}\right),
\end{gathered}
$$


where Constraint (7) is the intermediary-marketclearing condition.

3.1.4. Discussion. A few comments are in order. First, we focus on a static (one-shot) game because we study situations in settings such as fashion apparel and shoes where retailers contact intermediaries to satisfy incidental demand for new products. This context is well grounded in the literature, and is justified by several authors: Purvis et al. (2013) and Christopher et al. (2004).

Second, our model is based on wholesale price contracts. We do this because there is empirical support for their widespread usage and popularity (Lafontaine and Slade 2012), and moreover, there is ample precedence in the supply chain literature (see, for instance, Lariviere and Porteus 2001, Perakis and Roels 2007). ${ }^{3}$

Third, like M\&S we consider linearly increasing marginal costs of supply. ${ }^{4} \mathrm{M} \& S$ argue that an increasing marginal cost is required to achieve an equilibrium when the suppliers are followers in the supply chain. More importantly, this is the most realistic assumption in the context of intermediary firms that use the existing production capacity of their network of suppliers to satisfy incidental demand from retailers. Because the suppliers use existing capacity, they do not incur fixed costs due to capacity investments. ${ }^{5}$ In the absence of incremental fixed costs, it is sufficient to capture the variable costs, which inevitably increase as the order quantities approach the capacity constraint of the suppliers.

Although we choose a linear marginal cost function for suppliers for tractability, in Appendix B of Data S1, we show that our main finding - that the intermediary profits are unimodal with respect to the number of suppliers-also holds for a convex monomial marginal cost function. Note also that, although we do not explicitly include the supplier capacity constraints in our model, they are implicitly considered because in equilibrium a supplier would never produce a quantity larger than $\left(d_{1}-s_{1}\right) / s_{2}$, where $d_{1}\left(>s_{1}\right)$ is the intercept of the demand function.

\subsection{Equilibrium and Intermediary Profits}

The following theorem provides closed-form expressions for the equilibrium quantities, prices, and profits. The closed-form expressions are defined in terms of supply chain characteristics such as the number of suppliers, and the demand and supply sensitivities.

THEOREM 1. There exists a unique equilibrium for the supply chain with S symmetric suppliers, one intermediary, and one retailer. The equilibrium is symmetric among the suppliers, and the equilibrium quantities, prices, and aggregate profits are as follows: quantities: $Q \equiv q_{r}=q_{i}=S q_{s}=\frac{S\left(d_{1}-s_{1}\right)}{2\left(d_{2} S+2 s_{2}\right)}$;

prices: $p_{r}=d_{1}-d_{2} Q, \quad p_{i}=s_{1}+2 \frac{s_{2}}{S} Q$,

$$
p_{s}=s_{1}+\frac{s_{2}}{S} Q
$$

profits: $\pi_{r}=\frac{\left(d_{1}-s_{1}\right)}{2} Q, \quad \pi_{i}=\frac{s_{2} Q^{2}}{S}, \quad S \pi_{s}=\frac{s_{2} Q^{2}}{2 S}$.

We use the closed-form expressions in Theorem 1 to perform comparative statics. We first describe three intuitive monotonicity results that provide reassurance about the validity of the model. Straightforward calculations using the expressions obtained in Theorem 1 lead to the following observations.

1. The total quantity produced in the supply chain is increasing in the number of suppliers, and decreasing in the demand and supply sensitivities.

2. The prices at each tier are decreasing in the number of suppliers, increasing in the supply function sensitivity, and decreasing in the demand function sensitivity.

3. The retailer profit is increasing in the number of suppliers and decreasing in both the supply and demand sensitivities.

We also characterize the dependence of intermediary profits on the number of suppliers, which results in our main finding.

THEOREM 2. In the case with one retailer and one intermediary, the intermediary profit $\pi_{i}$ is unimodal and achieves a maximum with respect to the number of suppliers for $S=2 s_{2} / d_{2}$.

We find that, surprisingly, the intermediary margin decreases in the number of suppliers: $p_{i}-p_{s}=s_{2} Q / S$ $=s_{2}\left(d_{1}-s_{1}\right) / 2\left(d_{2} S+2 s_{2}\right)$. Moreover, the order quantity monotonically increases in the number of suppliers. Consequently, the intermediary profit is unimodal with respect to the number of suppliers. As a result, the intermediary profits reach their maximum for a finite number of suppliers. Based on the results in C\&K and Choi (1991), one might expect that the larger the supplier base, the larger the market power of the intermediary and thus the larger its margin and profit. This intuition holds when the size of the supplier base is "small." However, in a world where the retailer leads, when the supplier base is "large enough," we show that the weakness of the suppliers becomes the weakness of the intermediary, 
and the retailer exploits its leadership position to increase its market power and retain greater supply chain profits. To illustrate the intuition behind this phenomenon, consider the specific case in which there is an infinite number of suppliers. The retailer knows that the intermediary can get an unlimited quantity of the product at a price of $s_{1}$ per unit. As a result, the retailer can exploit its leader advantage to drive the intermediary price to the suppliers' marginal cost $s_{1}$. In this limiting case, the retailer has all the market power and keeps all profits.

A crucial implication of the result in Theorem 2 is that intermediaries in retailer-driven supply chains prefer products for which the supplier base (existing production capacity) is neither too narrow nor too broad (also refer to Remark 1 in this regard). This is because (ceteris paribus) products for which there is an intermediate production capacity generate larger intermediary profits. Theorem 2 also offers some insight into how the financial performance of intermediaries, and consequently of economies reliant on this sector, depends on the available production capacity. Along with demand, this capacity is also a function of various economic and environmental factors. For instance, Barrie (2013) reports a shortfall in available capacity for 2013 in the fashion apparel sector, whereas Zhao (2013) points to endemic overcapacity in the Chinese fashion industry during the 1980s and 1990s. Our analysis shows that intermediary profits will be squeezed in either of these two eventualities; that is, in case of shortfall or excess in available capacity. ${ }^{6}$

Given that we restricted our attention to a supply chain with one retailer and one intermediary, a natural question is: how would our main insights be affected by relaxing this restriction?

\section{The Impact of Horizontal Competition}

In this section, we study how our findings are affected by the presence of horizontal competition among retailers and intermediaries. This is a realistic feature of retailer-driven supply chains: intermediaries are often subject to fierce horizontal competition (Hsing 1999). Likewise, retailers, who often compete for consumer demand, also compete for the same set of intermediaries (Masson et al. 2007).

We first consider a supply chain where all intermediaries share all existing suppliers, and show that our main finding continues to hold in the presence of horizontal competition. We also show that the number of suppliers that maximizes intermediary profits decreases in the number of intermediaries. Finally, we characterize the efficiency of the decentralized supply chain, and show that the number of suppliers that maximizes the overall supply chain efficiency differs from that maximizing the intermediary profits. In section 5 we extend our analysis to the case with both exclusive and shared suppliers.

\subsection{Model}

We now consider the case of $I$ symmetric intermediaries and $R$ symmetric retailers. As discussed in section 3.1, following the existing literature, we assume retailers and intermediaries compete horizontally in quantities. A timeline of events for the three-tier supply chain with horizontal and vertical competition is depicted in Figure 1.

Given an intermediary price $p_{i}$, the $l$ th intermediary chooses its order quantity $q_{i, l}$ to maximize its profit, assuming the rest of the intermediaries keep their order quantities fixed, and anticipating the reaction of the suppliers. The lth intermediary decision may be written as:

$$
\begin{aligned}
& \max _{q_{i, l}, p_{s}}\left(p_{i}-p_{s}\right) q_{i, l} \\
& \text { s.t. } \quad q_{i, l}+Q_{i,-l}=Q_{s}\left(p_{s}\right),
\end{aligned}
$$

where $Q_{i,-l}$ is the total quantity ordered by the rest of the intermediaries, $Q_{s}\left(p_{s}\right)$ is the total quantity produced by suppliers when the supplier price is $p_{s}$, and Constraint (9) is the supplier-market-clearing condition.

The $k$ th retailer chooses its order quantity $q_{r, k}$ to maximize its profit, assuming the rest of the retailers keep their order quantities fixed, and anticipating the intermediary reaction:

$$
\begin{aligned}
& \max _{q_{r, k}, p_{i}}\left[d_{1}-d_{2}\left(q_{r, k}+Q_{r,-k}\right)-p_{i}\right] q_{r, k} \\
& \text { s.t. } \quad q_{r, k}+Q_{r,-k}=Q_{i}\left(p_{i}\right),
\end{aligned}
$$

where $Q_{r,-k}$ is the total quantity ordered by the rest of the retailers, $Q_{i}\left(p_{i}\right)$ is the intermediary equilibrium quantity for a price $p_{i}$, and Constraint (11) is the intermediary-market-clearing condition.

Figure 1 Timeline of Events

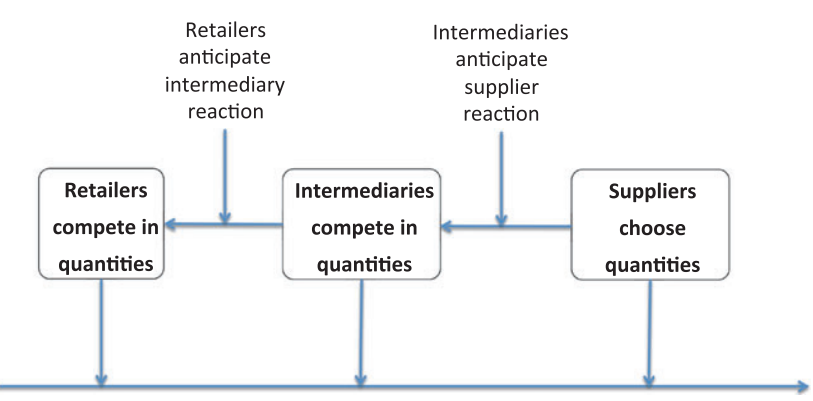


Consistent with the literature on multi-tier supplychain competition (i.e., $\mathrm{C} \& \mathrm{~K}$ and the references therein), we assume that the retailers and intermediaries compete in quantities. The alternative assumption of price competition with homogeneous products results in zero profit for the retailers and intermediaries, which is not realistic in our setting. Moreover, we have established that our main insight-intermediaries thrive when the supply base is neither too narrow nor too broad-holds for the case with a single retailer and a single intermediary. In this setting, it is easy to show that the equilibrium is identical for the cases where the retailer and the intermediary choose quantities or prices. This provides some reassurance that our main insight is not driven by the Cournot assumption.

\subsection{Equilibrium and Intermediary Profits}

The following theorem provides closed-form expressions that achieve our main objective: to characterize the profitability of intermediaries (and other players) in terms of various market conditions: namely, industry competitive structure, and the demand and supply characteristics.

THEOREM 3. There exists a unique equilibrium for the supply chain with multiple symmetric suppliers, intermediaries, and retailers. The equilibrium is symmetric, and the equilibrium quantities, prices and aggregate profits are as follows:

quantities: $Q \equiv R q_{r}=I q_{i}=S q_{s}$

$$
=\frac{R S I\left(d_{1}-s_{1}\right)}{(R+1)\left(d_{2} S I+(I+1) s_{2}\right)}
$$

prices: $\quad p_{r}=d_{1}-d_{2} Q, \quad p_{i}=s_{1}+\frac{s_{2}}{S} \frac{I+1}{I} Q$,

$$
p_{s}=s_{1}+\frac{s_{2}}{S} Q
$$

profits: $\quad R \pi_{r}=\frac{d_{1}-s_{1}}{R+1} Q, \quad I \pi_{i}=\frac{I s_{2} Q^{2}}{S I^{2}}, \quad S \pi_{s}=\frac{s_{2} Q^{2}}{2 S}$.

It is easy to see that the monotonicity results obtained for a single retailer and intermediary continue to hold for the case with competing retailers and intermediaries. In addition, Theorem 3 allows us to perform comparative statics with respect to the number of retailers and intermediaries. Straightforward calculations using the expressions obtained in Theorem 3 lead to the following observations:

1. The total quantity produced in the supply chain (or equivalently, volume of trade) increases in the number of retailers and intermediaries.
2. The prices at each tier decrease in the number of players in following tiers and increase in the number of players in leading tiers.

3. The aggregate retailer profit increases in the number of intermediaries but decreases in the number of retailers.

Finally, we use the closed-form expressions in Theorem 3 to study how our main finding is affected by the presence of competing retailers and intermediaries.

THEOREM 4. In the case with multiple competing retailers and intermediaries, at equilibrium, the aggregate intermediary profit $I \pi_{i}$ is unimodal and achieves a maximum with respect to the number of suppliers for $S=S_{\max } \equiv(I+1) s_{2} /\left(d_{2} I\right)$.

Theorem 4 shows that intermediary profits are unimodal in the number of suppliers even in the presence of horizontal competition. Moreover, the result shows that the number of suppliers that maximizes aggregate intermediary profits is lower in the presence of competition than otherwise. In other words, multiple competing intermediaries prefer a smaller supply base compared to a single intermediary. Because competition among intermediaries strengthens the bargaining position of the retailer, intermediaries prefer to carry products with a more inelastic supply side.

Figure 2 depicts the aggregate intermediary profit as a function of the number of suppliers for the cases with one retailer and two intermediaries $(R=1$, $I=2)$, and one retailer and one intermediary $(R=2$, $I=1$ ). The figure confirms that intermediary profits are unimodal in the number of suppliers even in the presence of horizontal competition. The figure also shows that competing intermediaries thrive with relatively smaller supplier bases (compare the number of suppliers that maximizes the intermediary profit for the case $R=1, I=2$ to that for the case $R=1, I=1$ ).

Given the result in Theorem 4, it is conceivable that intermediaries may prefer to carry products with a supply-base size that optimizes intermediary profits. How would this compare with the size of the supply base that maximizes the efficiency of the entire supply chain? We address this question next.

\subsection{Size of Supply Base and Supply Chain Efficiency}

We characterize the efficiency of the decentralized supply chain and compare the number of suppliers that maximizes intermediary profits with that maximizing supply chain efficiency. Following the supply chain literature, we define supply chain efficiency as the ratio between the decentralized supply chain 


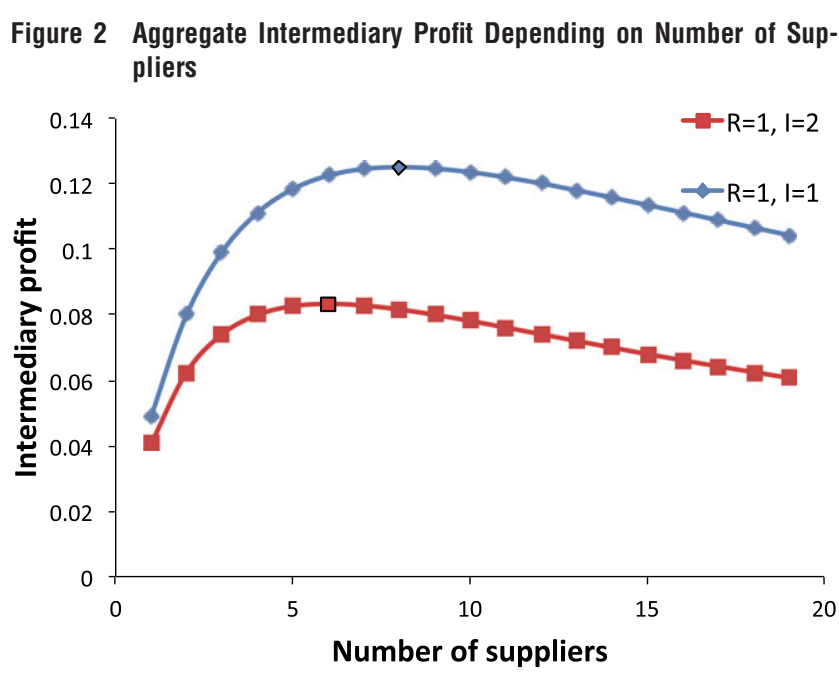

Notes: This figure depicts the aggregate intermediary profit for a number of suppliers ranging between 1 and 20 , and for the cases with one retailer and two intermediaries $(R=1, I=2)$, and one retailer and one intermediary $(R=2, I=1)$. We assume $d_{2}=1, s_{2}=4, s_{1}=3, d_{1}=5$. The horizontal axis gives the number of suppliers and the vertical axis gives the aggregate intermediary profit. The delineated marker indicates the highest aggregate intermediary profit.

profits and the centralized profits, which correspond to the case when a system planner chooses all quantities to maximize the total supply chain profits. The following proposition gives closed-form expressions of the supply chain efficiency and characterizes its dependence on the number of suppliers.

THEOREM 5. The supply chain efficiency is

Efficiency $=\frac{R I\left[s_{2} R(I+2)+2\left(d_{2} S I+s_{2}(I+1)\right)\right]}{\left(d_{2} S I+s_{2}(I+1)\right)^{2}} \frac{2 d_{2} S+s_{2}}{(R+1)^{2}}$.

Moreover, efficiency is unimodal with respect to the number of suppliers $S$ and reaches a maximum equal to one for $S^{*}=s_{2}(R+I+1) /\left(d_{2} I(R-1)\right)$ provided that $R>1$. If $R=1$, then the efficiency monotonically increases in the number of suppliers, and tends to one as $S \rightarrow \infty$.

Theorem 5 shows that the number $S^{*}$ of suppliers that maximizes the supply chain efficiency differs, in general, from the number $S_{\max }$ of suppliers that maximizes intermediary profits. In particular, the number $S^{*}$ of suppliers that maximizes efficiency is larger than the number $S_{\max }$ of suppliers that maximizes intermediary profit if and only if $R<2+2 / I$. This suggests that with high concentration in the retail tier (small $R$ ), intermediaries in a decentralized chain are likely to carry products with a smaller-than-efficient supply base. Thus, subsidizing the intermediaries to carry products with a larger supply base is likely to improve the overall efficiency. However, for supply chains with low retailer concentration (large $R$ ), such subsidies are unlikely to help. Our results suggest that if regulatory intervention is to succeed at improving the overall supply chain efficiency, it must be carefully tailored to the structure of the supply chain in question.

\section{The Case with Shared and Exclusive Suppliers}

In section 4, we assumed that all $I$ intermediaries share all $S$ suppliers. We now relax this assumption by considering a general model where each supplier works with an arbitrary subset of the intermediaries. This model captures situations where intermediaries have exclusive as well as shared suppliers, and situations where large intermediaries deal with many suppliers while small ones deal with only a few suppliers.

We find that our main finding continues to hold in the presence of shared and exclusive suppliers: intermediary profits continue to be unimodal with respect to the number of suppliers. Compared to the case analyzed in section 4, we find that the presence of some exclusive suppliers increases the number of suppliers that maximizes intermediary profits.

The following proposition shows that the equilibrium total quantity for the general case where the $j$ th supplier works with a subset of $I_{j}$ intermediaries is equivalent to the equilibrium total quantity for a supply chain where all $S$ suppliers work with a smaller number of intermediaries $\bar{I}$, which we term the effective number of intermediaries.

Proposition 1. The equilibrium total quantity for the general case where the jth supplier works with a subset of $I_{j}$ intermediaries is equivalent to the equilibrium total quantity for a supply chain where all $S$ suppliers work with $\bar{I} \in[1, I]$ intermediaries, where $\bar{I} \in[1, I]$ is such that

$$
\frac{\bar{I}}{\bar{I}+1}=\frac{1}{S} \sum_{j=1}^{S} \frac{I_{j}}{I_{j}+1} .
$$

This result shows that the presence of some exclusive suppliers has the same effect on the total quantity produced as a reduction of competition among intermediaries. This is because the effective number of intermediaries is lower than the true number of intermediaries.

Note that Proposition 1 is not enough to show the robustness of our main finding to the existence of exclusive suppliers because the profits received by the intermediaries depend not only on the aggregate quantity, but also on the precise structure of the 
supply chain. To establish the robustness of our findings, we now characterize the intermediary profits for two different cases: (i) a case where all suppliers are exclusive, and (ii) a case where some suppliers are shared and some are exclusive.

Proposition 2. Let every supplier work exclusively with a single intermediary, then

1. the supply chain equilibrium is equivalent to that of a supply chain where a single intermediary works with all $S$ suppliers,

2. the aggregate intermediary profits are unimodal in the total number of suppliers,

3. the aggregate intermediary profits are maximized when there are $2 s_{2} / d_{2}$ suppliers, where $2 s_{2} / d_{2}$ is larger than the number of suppliers that maximizes intermediary profits in the case where all suppliers are shared by all intermediaries, and

4. the aggregate intermediary profits are higher than for the case where all suppliers are shared by all intermediaries.

The intuition behind the proof of this proposition is that, because intermediaries are price-takers with respect to the retailers, the intermediary optimal order quantity for a particular supplier depends only on the number of other intermediaries working with that supplier. Therefore, for the case where every supplier is exclusive, the optimal order quantity and the total intermediary profits depend only on the number of suppliers, independently of whether they each work with a separate intermediary, or they all work for the same intermediary.

We now consider the case where some suppliers are shared and others exclusive. To simplify the exposition, we focus on the case where there are two intermediaries, each of which has some exclusive suppliers and also shares some suppliers with the other intermediary. The result can be extended to the case of many intermediaries. We study how intermediary profits depend on the total number of suppliers for the case where the proportion of shared and exclusive suppliers stays constant.

Proposition 3. Assume there are two intermediaries, and intermediary $l$ works with $S_{l}$ exclusive suppliers $(l=1,2)$ and $S_{12}$ shared suppliers. Moreover, assume that $S_{l}=\theta_{l} S$ and $S_{12}=\theta_{12} S$, with $\theta_{l}, \theta_{12}$ fixed $(l=1,2)$, such that $\theta_{1}+\theta_{2}+\theta_{12}=1$. Then,

1. the aggregate intermediary profits are unimodal in the total number of suppliers $S$, and

2. the aggregate intermediary profits are maximized when there are $\left(s_{2} / d_{2}\right)(\bar{I}+1) / \bar{I}$ suppliers, where $\left(s_{2} / d_{2}\right)(\bar{I}+1) / \bar{I}$ is larger than the number of suppliers that maximizes aggregate intermediary profits in the case where all suppliers are shared by all intermediaries.

Propositions 2 and 3 show that intermediaries continue to prefer products for which there exists an intermediate production capacity, but the presence of exclusive suppliers dampens the intensity of competition among intermediaries. As a result, intermediaries are willing to carry products with a relatively larger existing production capacity.

\section{The Option to Source Directly from the Suppliers}

We now study whether the ability of the retailer to source directly from the suppliers affects our main finding about the unimodality of the intermediary profit, and how it affects the optimal number of suppliers. To simplify exposition, we consider here the base case model with a single retailer and intermediary. The result can be easily extended to the case with horizontal competition among retailers and intermediaries.

We assume that if the retailer chooses to deal directly with the suppliers, the retailer incurs a fixed cost per supplier $F>0$, which represents the cost associated with establishing a working relation with each supplier. In addition, if the retailer chooses to deal directly with the suppliers, the retailer incurs an additional variable cost per unit $v \geq 0$. This additional variable cost captures the fact that it may be more expensive for the retailer to validate the quality of each unit purchased (compared to the experienced intermediary). If, on the other hand, the retailer decides to use the services of the intermediary, it simply pays a price per unit to the intermediary, who keeps a certain margin. The intermediary places its orders from the suppliers without incurring any fixed costs because it has an established relationship with its supplier base.

Our analysis consists of three steps: (i) we analyze the case where the retailer deals directly with the suppliers, (ii) we characterize the conditions under which the retailer prefers to use the services of the intermediary, and (iii) we study how the intermediary profit depends on the number of suppliers when the retailer can source directly from the suppliers.

\subsection{Direct Sourcing}

First, we characterize the retailer profits for the case where the retailer deals directly with the suppliers, which can be modeled as a two-stage game. In the first stage, the retailer chooses the number of suppliers to deal with $S_{R}$, incurring a fixed cost $S_{R} F$. In the second stage, the retailer chooses its order quantity. 
Proposition 4. Let the retailer deal directly with the suppliers, then

1. In the second stage (that is, for a given number of suppliers $S_{R}$ ), the equilibrium with no intermediary coincides with the equilibrium with an infinite number of intermediaries and where the intercept of the inverse demand function equals $d_{1}-v$.

2. The retailer profit in the first stage $\bar{\pi}_{r}$ is a strictly concave function of $S_{R}$. Moreover, the optimal number of suppliers ${ }^{8}$ selected by the retailers $S_{R}$ and the corresponding retailer profit net of transaction costs $\bar{\pi}_{r}$ are:

$$
\begin{aligned}
& S_{R}=\frac{1}{d_{2}}\left[\frac{\left(d_{1}-v-s_{1}\right) \sqrt{s_{2}}}{2 \sqrt{F}}-s_{2}\right]^{+}, \text {and } \\
& \bar{\pi}_{r}=\frac{s_{2}}{d_{2}}\left(\left[\frac{d_{1}-v-s_{1}}{2 \sqrt{s_{2}}}-\sqrt{F}\right]^{+}\right)^{2},
\end{aligned}
$$

where $[.]^{+}$is the positive part.

\subsection{To Intermediate or Not to Intermediate}

We now characterize the conditions under which the retailer uses the services of the intermediary. The retailer benefits from utilizing the intermediary when its profit in the case with the intermediary exceeds its profit without, i.e. when

$$
\frac{S\left(d_{1}-s_{1}\right)^{2}}{4\left(d_{2} S+2 s_{2}\right)} \geq \frac{s_{2}}{d_{2}}\left(\left[\frac{d_{1}-v-s_{1}}{2 \sqrt{s_{2}}}-\sqrt{F}\right]^{+}\right)^{2} .
$$

COROLlary 1. The retailer uses the intermediary when one of the following holds:

1. the fixed cost $F$ is sufficiently large,

2. the retailer additional variable cost $v$ is sufficiently large,

3. the number of suppliers is sufficiently large, or

4. the first unit margin $d_{1}-s_{1}$ is sufficiently small.

The results in Corollary 1 are consistent with intuition: a retailer prefers working with an intermediary when the fixed or variable costs associated with sourcing directly from the suppliers are high, when margins are low and thus it is not worth paying additional fixed or variable costs to deal with suppliers, or when the supplier base is large and thus the intermediary supply costs are lower than that of the retailer working directly with suppliers.

\subsection{Intermediary Profits and Size of Supplier Base} We now show that the intermediary profits continue to be unimodal even when the retailer has the option to deal directly with the suppliers. We also show, however, that the threat that the retailer may work directly with the suppliers may encourage the intermediary to carry products with a broader supplier base.

When the retailer does not have the option to work directly with the suppliers, we know from Theorem 2 that the intermediary profits are maximized for products with number of suppliers $S_{\max }=2 s_{2} / d_{2}$. However, from Part 3 of Corollary 1, we know that if the number of suppliers is smaller than $S_{\text {min }}$, then the retailer would choose to work directly with the suppliers, and this would result in zero profit for the intermediary. Faced with this threat, the intermediary may optimally choose to carry products with number of suppliers $\bar{S}>S_{\max }$. This intuition is formalized in the following proposition.

Corollary 2. Suppose the retailer has the option to deal directly with suppliers. In this case, the intermediary profit is unimodal in the number of suppliers, and the intermediary profit is maximized for a number of suppliers

$$
\bar{S}=\left\{\begin{array}{cc}
S_{\tau}>S_{\max } & \text { if } S_{\tau}>0 \text { and }(\sqrt{2}-1)\left(d_{1}-s_{1}\right) \\
S_{\max } & >\sqrt{2}\left(v+2 \sqrt{F_{s_{2}}}\right) \\
\text { otherwise }
\end{array}\right.
$$

where $\quad S_{\tau} \equiv 8 s_{2}^{2}\left([\vartheta-\sqrt{F}]^{+}\right)^{2} /\left(d_{2}\left[\left(d_{1}-s_{1}\right)^{2}-4 s_{2}\right.\right.$ $\left.\left.\times\left([\vartheta-\sqrt{F}]^{+}\right)^{2}\right]\right)$, and $\vartheta=\left(d_{1}-v-s_{1}\right) /\left(2 \sqrt{s_{2}}\right)$.

Corollary 2 implies that, when the condition in the first part of Equation (15) holds, the threat that the retailer may deal directly with suppliers gives the intermediary an incentive to carry products with a broader supplier base.

Figure 3 shows the intermediary profit as a function of the number of suppliers for two cases with different fixed cost $F$. The left panel has a higher fixed cost, and in this case the intermediary is better off working with $S_{\max }$ suppliers. The right panel has a lower fixed cost, and this pushes the intermediary to prefer working with a higher number of suppliers $S_{\tau}$. The intermediary profit is unimodal with respect to the number of suppliers in both cases.

\section{Conclusion}

We characterize the market conditions under which intermediaries thrive in a retailer-driven supply chain. Our main finding suggests that intermediaries prefer products for which the supply base is neither too broad nor too narrow. This result not only helps clarify the characteristics of products which are likely to be favored by intermediaries, but also helps explain 
Figure 3 Intermediary Profit Depending on Number of Suppliers with Direct Sourcing Option

(a) Intermediary Profit

$(\mathrm{F}=\mathbf{0 . 1})$

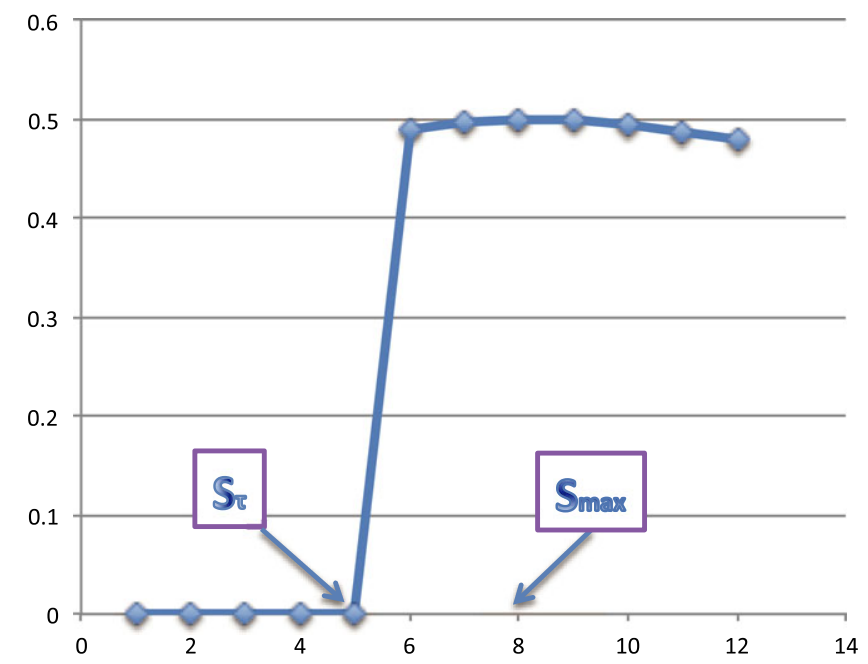

(b)
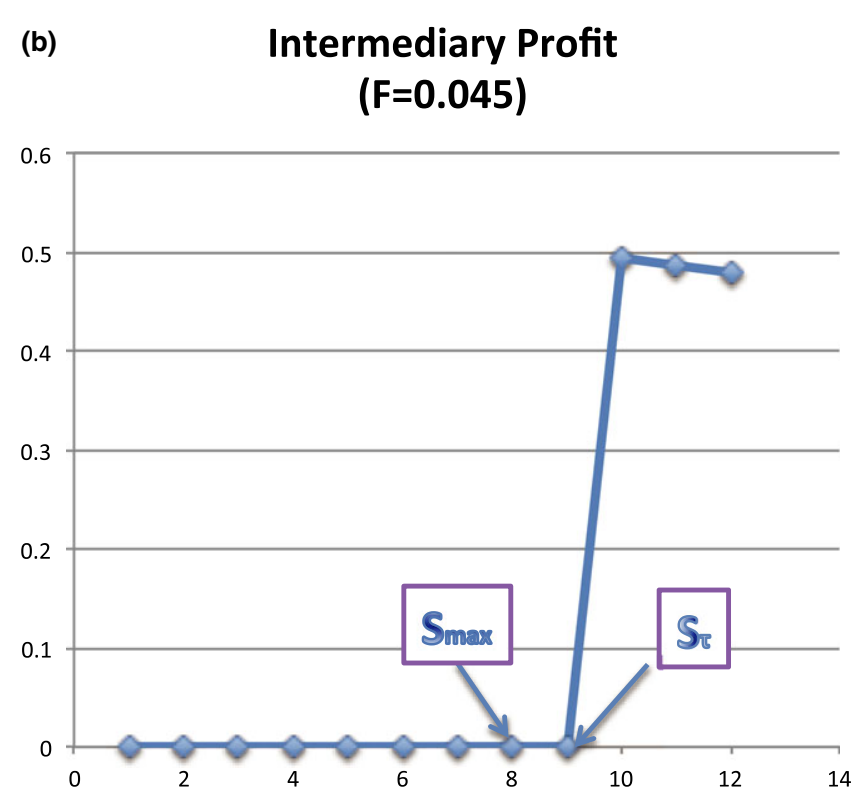

Notes: This figure depicts the aggregate intermediary profit for a number of suppliers ranging between 1 and 12, and for two different values of the fixed search cost $F$ when the retailer has the option to deal directly with suppliers. We assume $d_{2}=0.25, s_{2}=1, s_{1}=3, d_{1}=5, I=1, R=1, v=0.1$ and $F=0.1$ for the case depicted in the left panel, while $F=0.045$ for the case in the right panel. The horizontal axis gives the number of suppliers and the vertical axis gives the intermediary profit. $S_{\max }$ indicates the number of suppliers that maximizes the intermediary profit when the retailer does not have the option to deal directly with suppliers. $S_{\min }$ indicates the minimum number of suppliers required for the retailer to choose using the intermediary.

how the financial performance of intermediaries, and hence, of economies reliant on this sector, may vary depending upon the availability of supply.

Our main finding continues to hold in the presence of horizontal competition among retailers and intermediaries, the existence of shared and exclusive suppliers, and the ability of the retailers to source directly from the suppliers. We find, however, that the size of the supply base that maximizes intermediary profits decreases with horizontal competition among intermediaries, and increases with the existence of exclusive suppliers and direct sourcing.

Finally, our analysis sheds some light on the suggestion by Rauch (2001) that network intermediaries may not be adequately connecting buyers and sellers internationally. Specifically, our results show that, to maximize their profits, intermediaries may choose to carry products for which the existing capacity is intermediate. The capacity of the supplier base that maximizes the overall supply-chain efficiency, however, may be larger or smaller depending on the intensity of competition among retailers. This implies that, in order for policy intervention to be effective, it must be tailored to the specific characteristics of the supply chain in question.

\section{Acknowledgments}

We are grateful for comments from Vlad Babich, Elena Belavina, Long Gao, Karan Girotra, Serguei Netessine, Guil- laume Roels, Nicos Savva, Robert Swinney, Song (Alex) Yang, and seminar participants at the 2013 MSOM Supply Chain Management SIG Conference in Fontainebleau, the 2012 POMS Conference in Chicago, the 2012 MSOM Conference in New York, the 2012 INFORMS Annual Meeting in Phoenix, the 2011 INFORMS Annual Meeting in Charlotte, the Anderson Graduate School of Management at UC Riverside, ESSEC Business School, the department of Management Science and Innovation at University College London, the Stuart School of Business at Illinois Institute of Technology, and San Jose State University College of Business. Finally, this study is dedicated to our children: Livia, Talia, Nivedita, Sanjana, Marta, and Tomas, who were all born while we worked on this manuscript.

\section{Appendix A. Proofs for the Results in the Paper}

ProOF OF THEOREM 1. Using backwards induction, we start by considering the supplier tier. The $j$ th supplier optimally chooses to produce the quantity such that its marginal cost equals the supply price; that is, the quantity $q_{s, j}$ such that

$$
p_{s}=s_{1}+s_{2} q_{s, j} .
$$

This implies that the supplier profit is

$$
\pi_{s, j}=\frac{s_{2} q_{s, j}^{2}}{2}
$$


Using Equation (2) to eliminate the supplier price from the intermediary decision problem, we obtain the following equivalent decision problem for the intermediary:

$$
\max _{q_{i}}\left[p_{i}-\left(s_{1}+s_{2} \frac{q_{i}}{S}\right)\right] q_{i}
$$

It is clear that for a given intermediary price $p_{i}$, the quantity selected by the intermediary at equilibrium is

$$
q_{i}\left(p_{i}\right)=\frac{S\left(p_{i}-s_{1}\right)}{2 s_{2}}
$$

Using Equation (A4) to eliminate the intermediary price from the retailer decision problem, we obtain the following equivalent decision problem for the retailer:

$$
\max _{q_{r}}\left[d_{1}-d_{2} q_{r}-\left(s_{1}+\frac{2 s_{2}}{S} q_{r}\right)\right] q_{r}
$$

It is clear that the quantity selected by the retailer at equilibrium is

$$
q_{r}=\frac{S\left(d_{1}-s_{1}\right)}{2\left(d_{2} S+2 s_{2}\right)}
$$

From the market clearing conditions, $Q=q_{r}$ $=q_{i}=S q_{s, j}$ for all $j$. The expression for $p_{s}$ follows from Equation (A1); the expression for $p_{i}$ follows from Equation (A4); the expression for $p_{r}$ follows from Equation (5). Simple algebra leads to obtaining $S \pi_{s}=s_{2} Q^{2} /(2 S) ; \pi_{i}=s_{2} Q^{2} / S ; \pi_{r}=\left(d_{1}-s_{1}\right) Q / 2$.

Proof OF TheOREM 2. The result follows from straightforward calculations using the expressions obtained in Theorem 1.

Proof of Theorem 3. We prove the result in three steps. First, we characterize the best response of the intermediaries to the retailers. Second, we characterize the retailer equilibrium as leaders with respect to the intermediaries. Third, simple substitution into the best response functions leads to the closed form expressions.

Step 1. The intermediary best response. We first show that the intermediary equilibrium best response exists, is unique, and is symmetric. It is easy to see that the intermediary decision problem

$$
\max _{q_{i, l}}\left[p_{i}-\left(s_{1}+s_{2} \frac{q_{i, l}+Q_{i,-l}}{S}\right)\right] q_{i, l}
$$

is a strictly concave problem that can be equivalently rewritten as a linear complementarity problem (LCP); see Cottle et al. (2009) for an introduction to complementarity problems. Hence, the intermediary order vector $q_{i}=\left(q_{i, 1}, \ldots, q_{i, I}\right)$ is an intermediary equilibrium if and only if it solves the following LCP, which is obtained by concatenating the LCPs characterizing the best response of the $I$ intermediaries $0 \leq\left(-p_{i}+s_{1}\right) e+\left(s_{2} / S\right) M_{i} q_{i} \perp q_{i} \geq 0$, where $e$ is the $I$-dimensional vector of ones, and $M_{i} \in \mathbb{R}^{I} \times \mathbb{R}^{I}$ is a positive definite matrix whose diagonal elements are all equal to one and whose off-diagonal elements are all equal to two. Thus, this LCP has a unique solution which is the unique intermediary equilibrium best response. Because the intermediary equilibrium is unique and the game is symmetric with respect to all intermediaries, the intermediary equilibrium must be symmetric. Indeed, if the equilibrium was not symmetric, because the game is symmetric with respect to all intermediaries, it would be possible to permute the strategies among intermediaries and obtain a different equilibrium, thereby contradicting the uniqueness of the equilibrium.

We now characterize the intermediary equilibrium best response. To avoid the trivial case where the quantity produced equals zero, we assume the equilibrium production quantity is nonzero. In this case, for the symmetric equilibrium, the first-order optimality conditions for the intermediary are: $p_{i}-\left(s_{1}+s_{2} Q / S\right)-s_{2} Q /(S I)=0$, where $Q$ is the aggregate intermediary order quantity, aggregated over all intermediaries. Hence, the intermediary price can be written at equilibrium as

$$
p_{i}=s_{1}+s_{2} \frac{I+1}{S I} Q .
$$

Note that the intermediary margin is therefore $m_{i}=p_{i}-p_{s}=s_{2} Q /(S I)$, and the intermediary profit is

$$
\pi_{i}=m_{i} \frac{Q}{I}=\frac{S_{2} Q^{2}}{S I^{2}} .
$$

Step 2. The retailer equilibrium. We first show that the retailer equilibrium exists, is unique, and is symmetric. The $k$ th retailer decision is

$$
\begin{aligned}
\max _{q_{r, k}} & {\left[d_{1}-d_{2}\left(q_{r, k}+Q_{r,-k}\right)\right.} \\
& \left.-\left(s_{1}+s_{2} \frac{I+1}{S I}\left(q_{r, k}+Q_{r,-k}\right)\right)\right] q_{r, k} .
\end{aligned}
$$

It is easy to see from Equation (A8) that the retailer problem is a strictly concave problem that can be equivalently rewritten as an LCP. Hence, the retailer 
order vector $q_{r}=\left(q_{r, 1}, \ldots, q_{r, R}\right)$ is a retailer equilibrium if and only if it solves the following LCP, which is obtained by concatenating the LCPs characterizing the optimal strategy of the $R$ retailers: $0 \leq\left(-d_{1}+s_{1}\right) e+\left(d_{2}+s_{2}(I+1) /(S I)\right) M_{r} q_{r} \perp q_{r} \geq$ 0 , where $e$ is the R-dimensional vector of ones, and $M_{r} \in \mathbb{R}^{R} \times \mathbb{R}^{R}$ is a positive definite matrix whose diagonal elements are all equal to two and whose off-diagonal elements are all equal to one. Thus, this LCP has a unique solution which is the unique retailer equilibrium. Using an argument similar to the intermediary equilibrium, the retailer equilibrium must be symmetric.

We now characterize the retailer equilibrium. To avoid the trivial case where the quantity produced equals zero, we focus on the more interesting case with nonzero quantities. For the symmetric equilibrium, the first-order optimality conditions for the retailer can be written as $d_{1}-s_{1}-\left(d_{2}+\right.$ $\left.s_{2}(I+1) /(S I)\right)(R+1) q_{r, k}=0$, and therefore assuming $d_{1} \geq s_{1}$, we have that the optimal retailer order quantity is

$$
q_{r, k}=\frac{d_{1}-s_{1}}{(R+1)\left(d_{2}+s_{2} \frac{I+1}{S I}\right)}=\frac{S I}{\left(d_{2} S I+s_{2}(I+1)\right)} \frac{d_{1}-s_{1}}{(R+1)},
$$

the intermediary price is

$$
p_{i}=s_{1}+s_{2} \frac{R(I+1)}{d_{2} S I+s_{2}(I+1)} \frac{d_{1}-s_{1}}{(R+1)},
$$

and the retailer profit is

$$
\begin{aligned}
\pi_{r}= & {\left[d_{1}-s_{1}-\left(d_{2}+s_{2} \frac{I+1}{S I}\right) \frac{R}{R+1} \frac{d_{1}-s_{1}}{\left(d_{2}+s_{2} \frac{I+1}{S I}\right)}\right] } \\
& \times \frac{1}{R+1} \frac{d_{1}-s_{1}}{\left(d_{2}+s_{2} \frac{I+1}{S I}\right)} \\
= & \frac{S I\left(d_{1}-s_{1}\right)^{2}}{\left(d_{2} S I+s_{2}(I+1)\right)(R+1)^{2}} .
\end{aligned}
$$

Step 3. Derivation of the final results. It follows from Equation (A9) that

$$
Q=R q_{r, k}=\frac{R S I}{\left(d_{2} S I+s_{2}(I+1)\right)} \frac{d_{1}-s_{1}}{(R+1)} .
$$

Since $q_{s, j}=Q / S$, the expression for the supply price follows from Equation (1). The expression for the intermediary price follows from Equations (A6) and (A11). The retailer price is obtained by substituting Equation (A11) into (5). Expressions for $m_{i}=p_{i}-p_{s}$ and $m_{r}=p_{r}-p_{i}$ are obtained by direct substitution. Using $q_{s, j}=Q / S$, Equations (A2) and (A11), we obtain the supplier profit. Substituting Equation (A11) into (A7) leads to the expression for the intermediary profit. The expression for $\pi_{r}$ was found in Equation (A10). Finally, the total aggregate profit follows from straightforward algebra.

Proof of TheOrem 4. The result follows from straightforward calculations using the expressions obtained in Theorem 3.

Proof of Theorem 5. The objective of a central planner is to maximize the sum of the profits of all supply chain members:

$$
\begin{aligned}
\max \pi_{c}= & S\left(p_{S}-s_{1}-\frac{s_{2}}{2} q_{S}\right) q_{S}+I\left(p_{i}-p_{S}\right) q_{I} \\
& +R\left(p_{r}-p_{i}\right) q_{R}
\end{aligned}
$$

where $q_{S}, q_{I}$ and $q_{R}$ are respectively the quantities selected by each supplier, intermediary and retailer. Since $Q=S q_{S}=I q_{I}=R q_{R}$, the central planner's problem is equivalent to

$\max \pi_{c}=\left(p_{r}-s_{1}-\frac{s_{2}}{2} \frac{Q}{S}\right) Q=\left(d_{1}-d_{2} Q-s_{1}-\frac{s_{2}}{2} \frac{Q}{S}\right) Q$.

The first-order optimality conditions are $d_{1}-s_{1}-2$ $\left(d_{2}+s_{2} / 2 S\right) Q=0$, which result in $Q=\left(d_{1}-s_{1}\right) /$ $\left(2 d_{2}+s_{2} / S\right)$. Therefore the total supply chain profit in the centralized chain is

$$
\begin{aligned}
\pi_{c} & =\left[d_{1}-s_{1}-\left(d_{2}+\frac{s_{2}}{2 S}\right) \frac{d_{1}-s_{1}}{2 d_{2}+\frac{s_{2}}{S}}\right] \frac{d_{1}-s_{1}}{2 d_{2}+\frac{s_{2}}{S}} \\
& =\frac{\left(d_{1}-s_{1}\right)^{2}}{2\left(2 d_{2}+\frac{s_{2}}{S}\right)} .
\end{aligned}
$$

Equation (12) is obtained by direct substitution of the aggregate profit given in Theorem 3 and Equation (A12). The monotonicity properties follow by applying straightforward calculus to the partial derivatives of the efficiency with respect to $R, S$, and $I$.

Proof of Proposition 1. Consider $S$ suppliers, $I$ intermediaries, and $R$ retailers. Suppliers may be shared or exclusive to intermediaries. Supplier $j$ works with $I_{j}$ intermediaries. One intermediary can offer different prices to different suppliers. The supplier price depends on the total quantity supplied by this supplier (to all the intermediaries that he works with).

Denote $\mathcal{I}_{j}$ the set of $I_{j}$ intermediaries that the $j$ th supplier works with. Those intermediaries offer the supplier a price $p_{s}^{j}$ such that:

$$
p_{s}^{j}=s_{1}+s_{2} \sum_{l \in \mathcal{I}_{j}} q^{j, l}
$$


where $q^{j, l}$ is the quantity that the $j$ th supplier provides to the $l$ th intermediary.

Intermediaries are price-takers. Given $p_{i}$, for each supplier $j$ that he works with, the $l$ th intermediary chooses quantity $q^{j, l}$ to maximize profits:

$$
\max \left[p_{i}-p_{s}^{j}\right] q^{j, l}
$$

Since $p_{s}^{j}=s_{1}+s_{2} \sum_{l^{\prime} \in \mathcal{I}} q^{j, l^{\prime}}=s_{1}+s_{2}\left(q^{j, l}+Q_{s}^{j,-l}\right)$, where $Q_{s}^{j,-l}$ is the quantity provided by the $j$ th supplier to intermediaries other than the $l$ th within set $\mathcal{I}_{\mid}$, the $l$ th intermediary's problem for the $j$ th supplier can be written:

$$
\max \left[p_{i}-s_{1}-s_{2}\left(q^{j, l}+Q_{s}^{j,-l}\right)\right] q^{j, l} .
$$

The $l$ th intermediary decision problem for the $j$ th supplier is a strictly concave problem that can be equivalently rewritten as a LCP

$$
0 \leq-p_{i}+s_{1}+2 s_{2} q^{j, l}+s_{2} \sum_{l^{\prime} \neq l, l^{\prime} \in \mathcal{I}_{\mid}} q^{j, l^{\prime}} \perp q^{j l} \geq 0 .
$$

Concatenating the LCPs of all intermediaries who work with the $j$ th supplier, we find that the $j$ th supplier order quantity vector $\hat{q}^{j}=\left(q^{j l}\right)_{l \in \mathcal{I}_{j}}$ is an equilibrium if and only if it solves the LCP

$$
0 \leq\left(-p_{i}+s_{1}\right) e^{j}+M^{j} \hat{q}^{j} \perp \hat{q}^{j} \geq 0,
$$

where $M^{j}$ is a square positive definite matrix of size $I_{j}$ with two on the diagonal and one on the off-diagonal entries, and $e^{j}$ is a vector of size $I_{j}$ with one for each component. Thus this LCP has a unique solution which is the unique intermediary best response for the $j$ th supplier. Note that each of the intermediaries working with the $j$ th supplier is facing the same problem for this supplier. Because the equilibrium is unique, it must be symmetric across those intermediaries. It follows that $q^{j, l}=q^{j, l^{\prime}}$ for all $l, l^{\prime}$ within set $\mathcal{I}_{j}$. Hence, $Q_{s}^{j,-l}=\left(I_{j}-1\right) q^{j, l}$ and

$$
p_{i}=s_{1}+s_{2}\left(I_{j}+1\right) q^{j, l},
$$

i.e.,

$$
q^{j, l}=\frac{p_{i}-s_{1}}{s_{2}\left(I_{j}+1\right)} .
$$

The total quantity supplied by supplier $j$ is

$$
Q_{j}=I_{j} q^{j, l}=\frac{p_{i}-s_{1}}{s_{2}} \frac{I_{j}}{I_{j}+1} .
$$

The total quantity supplied jointly by all suppliers is

$$
Q=\sum_{j} Q_{j}=\frac{p_{i}-s_{1}}{s_{2}} \sum_{j} \frac{I_{j}}{I_{j}+1} .
$$

It is easy to notice that there exists $\bar{I} \in[1, I]$ such that $\frac{\bar{I}}{\bar{I}+1}=\frac{1}{S} \sum_{j=1}^{S} \frac{I_{j}}{I_{j}+1} \in[0.5,1]$. Then we have

$$
Q=\frac{p_{i}-s_{1}}{s_{2}} S \frac{\bar{I}}{\bar{I}+1} \text {. }
$$

Therefore, the retailer equilibrium, the intermediary price and the aggregate quantity in the general case where each supplier works with $I_{j}$ intermediaries are the same as for the case where all suppliers work with $\bar{I}$ intermediaries.

Using the proof of Theorem 3, we get

$$
Q=\frac{R S \bar{I}}{d_{2} S \bar{I}+s_{2}(\bar{I}+1)} \frac{d_{1}-s_{1}}{R+1} .
$$

In particular, it follows that

$$
\frac{p_{i}-s_{1}}{s_{2}}=\frac{R(\bar{I}+1)}{d_{2} S \bar{I}+s_{2}(\bar{I}+1)} \frac{d_{1}-s_{1}}{R+1} .
$$

The lth intermediary's profit is

$$
\begin{aligned}
\pi_{i}^{l} & =\sum_{j: l \in \mathcal{I}_{j}}\left(p_{i}-p_{s}^{j}\right) q^{j, l} \\
& =\sum_{j: l \in \mathcal{I}_{j}}\left(s_{1}+s_{2}\left(I_{j}+1\right) q^{j, l}-s_{1}-s_{2} I_{j} q^{j, l}\right) q^{j, l} \\
& =s_{2} \sum_{j: l \in \mathcal{I}_{j}}\left(q^{j, l}\right)^{2} .
\end{aligned}
$$

Proof of Proposition 2. Suppose that the $l$ th intermediary works with a group of $S^{l}$ exclusive suppliers. We have $\sum_{l} S^{l}=S$. For all $j, I_{j}=1$ so $\bar{I}=1$. Using Equation (A15), the lth intermediary's profit is

$$
\pi_{i}^{l}=S^{l} s_{2}\left(q^{j, l}\right)^{2} .
$$

We have

$$
Q=\frac{R S}{d_{2} S+2 s_{2}} \frac{d_{1}-s_{1}}{R+1} .
$$

Because the different suppliers are not linked via any constraint, the intermediary's decision about which quantity to order from a given supplier is independent from those about other suppliers. As every supplier is exclusive, this case is equivalent to the case with a single intermediary working with all suppliers, and thus each supplier gets the same order quantity:

Hence,

$$
q^{j, l}=Q / S=\frac{R}{d_{2} S+2 s_{2}} \frac{d_{1}-s_{1}}{R+1} .
$$

$$
\pi_{i}^{l}=\frac{S^{l}}{\left(d_{2} S+2 s_{2}\right)^{2}} \frac{s_{2} R^{2}\left(d_{1}-s_{1}\right)^{2}}{(R+1)^{2}} .
$$


Hence the aggregate intermediary profits are

$$
\sum_{l} \pi_{i}^{l}=\frac{S}{\left(d_{2} S+2 s_{2}\right)^{2}} \frac{s_{2} R^{2}\left(d_{1}-s_{1}\right)^{2}}{(R+1)^{2}} .
$$

It is clear that the aggregate intermediary profits are unimodal in $S$, reaching a maximum for $S=2 s_{2} /$ $d_{2}>(I+1) s_{2} /\left(I d_{2}\right)=S_{\max }$ suppliers. Finally, it is straightforward from Theorem 3 to find that the intermediary profits when all suppliers are shared are given by

$$
\frac{S}{\left(d_{2} S I+(I+1) s_{2}\right)^{2}} \frac{s_{2} R^{2} I\left(d_{1}-s_{1}\right)^{2}}{(R+1)^{2}}
$$

and are decreasing in $I$. Moreover, the aggregate intermediary profits when suppliers are exclusive match expression (A16) after substituting $I=1$. Hence, the intermediary profits when suppliers are exclusive are higher than when they are shared.

ProOf OF Proposition 3. Suppose two intermediaries (intermediary 1 and intermediary 2) work with respectively $S_{1}=\theta_{1} S$ and $S_{2}=\theta_{2} S$ exclusive suppliers, as well as $S_{12}=\theta_{12} S$ shared suppliers. Thus $S=S_{1}+S_{2}+S_{12}$, i.e. $\theta_{1}+\theta_{2}+\theta_{12}=1$. For each exclusive supplier, $I_{j}=1$ and for each shared supplier, $I_{j}=2$. It follows that

$$
\begin{aligned}
S \frac{\bar{I}}{\bar{I}+1} & =\sum_{j} \frac{I_{j}}{I_{j}+1}=\left(S_{1}+S_{2}\right) \frac{1}{1+1}+S_{12} \frac{2}{2+1} \\
& =\frac{S_{1}+S_{2}}{2}+\frac{2 S_{12}}{3}
\end{aligned}
$$

and hence

$$
\bar{I}=\frac{1}{1-\frac{1}{S}\left(\frac{S_{1}+S_{2}}{2}+\frac{2 S_{12}}{3}\right)}-1=\frac{1}{1-\left(\frac{\theta_{1}+\theta_{2}}{2}+\frac{2 \theta_{12}}{3}\right)}-1 .
$$

We have

$$
Q=\frac{R S \bar{I}}{d_{2} S \bar{I}+s_{2}(\bar{I}+1)} \frac{d_{1}-s_{1}}{R+1} .
$$

Denote $q_{e}$ the quantity provided to the intermediary by an exclusive supplier, and $q_{s}$ the quantity provided to each intermediary by a shared supplier. Using Equation (A15), the lth intermediary's profit is

$$
\pi_{i}^{l}=s_{2}\left(S_{l} q_{e}^{2}+S_{12} q_{s}^{2}\right)
$$

Using Equation (A13), we have

$$
q_{e}=\frac{p_{i}-s_{1}}{2 s_{2}}, \quad q_{s}=\frac{2}{3} \frac{p_{i}-s_{1}}{s_{2}} .
$$

Using Equation (A14), it follows that

$$
\begin{aligned}
q_{e}= & \frac{1}{2} \frac{R(\bar{I}+1)}{d_{2} S \bar{I}+s_{2}(\bar{I}+1)} \frac{d_{1}-s_{1}}{R+1}, \\
& q_{s}=\frac{2}{3} \frac{R(\bar{I}+1)}{d_{2} S \bar{I}+s_{2}(\bar{I}+1)} \frac{d_{1}-s_{1}}{R+1} .
\end{aligned}
$$

Thus the $l$ th intermediary profit is

$$
\pi_{i}^{l}=s_{2}\left(\frac{R(\bar{I}+1)}{d_{2} S \bar{I}+s_{2}(\bar{I}+1)} \frac{d_{1}-s_{1}}{R+1}\right)^{2}\left(\frac{S_{l}}{4}+\frac{4}{9} S_{12}\right) .
$$

It follows that the aggregate intermediary profits are

$$
\begin{aligned}
\pi_{i}^{1}+\pi_{i}^{2}= & s_{2}\left(\frac{\theta_{1}+\theta_{2}}{4}+\frac{8}{9} \theta_{12}\right)\left(R(\bar{I}+1) \frac{d_{1}-s_{1}}{R+1}\right)^{2} \\
& \times \frac{S}{\left(d_{2} S \bar{I}+s_{2}(\bar{I}+1)\right)^{2}} .
\end{aligned}
$$

Using Equation (A17), we find that $\bar{I}$ is independent of $S$. Then it is easy to see that the aggregate intermediary profits are unimodal with respect to the number of suppliers, achieving a maximum for $s_{2}(\bar{I}+1) /\left(d_{2} \bar{I}\right)$ suppliers. This number of suppliers is less than or equal to $(I+1) s_{2} /\left(I d_{2}\right)=S_{\max }$ because $\bar{I} \leq I$.

Proof of Proposition 4. Part 1. We assume that there are $S_{R}$ symmetric suppliers, but no intermediary. The demand function remains $p_{r}=d_{1}-d_{2} Q$. Following the reasoning detailed in previous sections, the retailer's decision problem can be formulated as $\max _{q_{r}}\left[d_{1}-d_{2} q_{r}-\left(s_{1}+\left(s_{2} / S_{R}\right) q_{r}\right)-v\right] q_{r}$, which is identical to Equation (A8) with $(I+1) / I=$ 1 (and $Q_{r,-k}=0$ ), i.e. $I=\infty$, and with an intercept of the consumer inverse demand function equal to $d_{1}-v$.

Part 2. In the first stage, the retailer chooses a number of suppliers $S_{R}$ to maximize her profits net of fixed costs. Using Theorem 3 and Proposition 4 part 1, we can write the first-stage retailer decision as:

$$
\max _{S_{R} \geq 0} \bar{\pi}_{r}=\frac{S_{R}}{d_{2} S_{R}+s_{2}} \frac{\left(d_{1}-v-s_{1}\right)^{2}}{4}-S_{R} F .
$$

We have

$$
\begin{aligned}
\frac{\partial \bar{\pi}_{r}}{\partial S_{R}} & =\frac{\left(d_{1}-v-s_{1}\right)^{2}}{(R+1)^{2}} \frac{s_{2}}{\left(d_{2} S_{R}+s_{2}\right)^{2}}-F \text { and } \\
\frac{\partial^{2} \bar{\pi}_{r}}{\partial S_{R}^{2}} & =-\frac{\left(d_{1}-v-s_{1}\right)^{2}}{(R+1)^{2}} \frac{2 s_{2} d_{2}}{\left(d_{2} S_{R}+s_{2}\right)^{3}}<0,
\end{aligned}
$$

and thus the concavity result follows. Then, using first-order optimality conditions in the presence of a 
non-negativity constraint, we obtain that the optimal value of $S_{R}$ is the solution to $s_{2}\left(d_{1}-v-s_{1}\right)^{2} /$ $\left(\left(d_{2} S_{R}+s_{2}\right)^{2}(R+1)^{2}\right)=F$ if this solution is non-negative, and otherwise $S_{R}=0$.

Proof OF Corollary 1. The result follows by straightforward algebraic manipulation of Equation (14).

Proof OF Corollary 2. It is straightforward that $\bar{S}=\max \left\{S^{*}, S_{\min }\right\}$. Algebraic manipulation of the expression of $S_{\text {min }}$ given in Corollary 2 leads to finding that $S_{\min }=\gamma S^{*}$ where

$$
\gamma=\frac{4 s_{2}\left(\left[\frac{d_{1}-v-s_{1}}{2 \sqrt{s_{2}}}-\sqrt{F}\right]^{+}\right)^{2}}{\left(d_{1}-s_{1}\right)^{2}-4 s_{2}\left(\left[\frac{d_{1}-v-s_{1}}{2 \sqrt{s_{2}}}-\sqrt{F}\right]^{+}\right)^{2}} .
$$

It is easy to find that $\gamma>1$ (i.e., $S_{\min }>S^{*}$ ) iff

$$
\left[\frac{d_{1}-v-s_{1}}{2 \sqrt{s_{2}}}-\sqrt{F}\right]^{+}>0
$$

and

$$
2\left(d_{1}-s_{1}-v-2 \sqrt{F s_{2}}\right)^{2}>\left(d_{1}-s_{1}\right)^{2},
$$

which is equivalent to condition (15).

\section{Notes}

${ }^{1}$ To see this, note that confronted with a heterogeneous (in cost) supply base, the intermediaries would first order from the cheapest supplier (up to its maximum capacity) and then engage with progressively more expensive suppliers. Such a supplier selection procedure would result in an increasing aggregate marginal cost function (common to all intermediaries) that could be approximated with a linearly increasing marginal cost function: $c^{\prime}(Q)=$ $s_{1}+\hat{s}_{2} * Q$ with $\hat{s}_{2}>0$. It is easy to see that the equilibrium and the insights from our model would not change much if we used this aggregate supply function provided that $\hat{s}_{2}=s_{2} / S$.

${ }^{2}$ Linear demand models have been widely used both in the Economics literature (see, for instance, Häckner 2003, Singh and Vives 1984) as well as in the Operations Management literature (C\&K, Farahat and Perakis 2009, Farahat and Perakis 2011).

${ }^{3}$ We have also considered a model where the retailer offers a two-part tariff to the intermediary. However, we find that as the retailer sets the contract terms to maximize its own profit while guaranteeing a reservation profit to the intermediary, the intermediary earns exactly its reservation profit, leaving all surplus to the retailer. Thus, this is not adequate to model intermediation because, as explained in Rauch (2001, p. 1196), intermediaries do keep a margin, but they have little leverage to raise their payoff through side payments or other means.
${ }^{4}$ In addition to M\&S, other authors who have assumed increasing marginal costs include Anand and Mendelson (1997), Correa et al. (2014), and Ha et al. (2011).

${ }^{5}$ One of the key rationales for modeling decreasing marginal cost of supply (economies of scale) is that any fixed cost of capacity investment can be defrayed over multiple units.

${ }^{6}$ Note that we do not consider the number of suppliers to be a decision of the intermediary: the number of suppliers in the intermediary's supplier base is determined by the extent of its existing relationships with local suppliers. Changing the number of suppliers is a long-term decision (e.g., aided by regulatory intervention), whereas our model is intended to capture a shorter time horizon.

${ }^{7}$ Theorem 5 shows that a single retailer $(R=1)$ recovers full efficiency for the case with an infinite number of suppliers. The reason for this is that in this case the supplier and intermediary margins converge to zero, and the retailer effectively manages the entire supply chain as a monopolist.

${ }^{8}$ Note that although $S_{R}$ should be an integer, for tractability we approximate the integer problem with its continuous relaxation and do not impose integrality constraints on $S_{R}$. Due to the concavity of the formulation, as shown in Proposition 4 part 2, the optimal integer value is the integer below or above the solution of the continuous relaxation.

\section{References}

Adida, E., V. DeMiguel. 2011. Supply chain competition with multiple manufacturers and retailers. Oper. Res. 59 (1): 156172.

Anand, K. S., H. Mendelson. 1997. Information and organization for horizontal multimarket coordination. Manage. Sci. 43 (12): 1609-1672.

Babich, V., Z. Yang, 2014. Does a procurement service provider generate value for the buyer through information about supply risks? Manage. Sci. 61 (5): 979-998.

Barrie, L. 2013. Outlook 2013. Apparel industry challenges. Available at http://www.just-style.com/management-briefing/apparel-industry-challenges_id116806.aspx. (accessed date July 7, 2015).

Belavina, E., K. Girotra. 2012. Global sourcing through intermediaries. Manage. Sci. 58 (9): 1614-1631.

Bernstein, F., A. Federgruen. 2005. Decentralized supply chains with competing retailers under demand uncertainty. Manage. Sci. 51 (1): 18-29.

Biglaiser, G. 1993. Middlemen as experts. Rand J. Econ. 24 (2): 212-223.

Cachon, G. P., M. A. Lariviere. 2005. Supply chain coordination with revenue-sharing contracts: strengths and limitations. Manage. Sci. 51 (1): 30-44.

Carr, S. M., U. S. Karmarkar. 2005. Competition in multi-echelon assembly supply chains. Manage. Sci. 51 (1): 45-59.

Cho, S. H. 2014. Horizontal mergers in multitier decentralized supply chains. Manage. Sci. 60 (2): 356-379.

Choi, S. C. 1991. Price competition in a channel structure with a common retailer. Mark. Sci. 10 (4): 271-296.

Christopher, M., R. Lowson, H. Peck, 2004. Creating agile supply chains in the fashion industry. Int. J. Retail Distrib. Manag. 32 (8): 367-376. 
Adida, Bakshi, and DeMiguel: Sourcing Through Intermediaries Production and Operations Management 25(4), pp. 630-646, (c) 2015 Production and Operations Management Society

Corbett, C. J., U. S. Karmarkar. 2001. Competition and structure in serial supply chains with deterministic demand. Manage. Sci. 47 (7): 966-978.

Correa, J. R., N. Figueroa, R. Lederman, N. E. Stier-Moses. 2014. Pricing with markups in industries with increasing marginal costs. Math. Program. Ser. A 146 (1): 143-184.

Cottle, R. W., J. -S. Pang, R. E. Stone. 2009. The Linear Complementarity Problem. Society for Industrial and Applied Mathematics, Philadelphia, PA.

Farahat, A., G. Perakis. 2009. Profit loss in differentiated oligopolies. Oper. Res. Lett. 37 (1): 43-46.

Farahat, A., G. Perakis. 2011. Technical note-A comparison of Bertrand and Cournot profits in oligopolies with differentiated products. Oper. Res. 59 (2): 507-513.

Federgruen, A., M. Hu. 2013. Sequential multi-product price competition in supply chain networks. Working paper, Rotman School of Management.

Ha, A., S. Tong, H. Zhang. 2011. Sharing demand information in competing supply chains with production diseconomies. Manage. Sci. 57 (3): 566-581.

Ha-Brookshire, J., B. Dyer. 2008. Apparel import intermediaries the impact of a hyperdynamic environment on U.S. apparel firms. Clothing Text. Res. J. 26 (1): 66-90.

Häckner, J. 2003. A note on price and quantity competition in differentiated oligopolies. J. Econ. Theory 93 (2): 223-239.

Hsing, Y. 1999. Trading companies in Taiwan's fashion shoe networks. J. Int. Econ. 48 (1): 101-120.

Knowledge@Wharton. 2007. Li and Fung's Bruce Rockowitz: Managing supply chains in a "flat" world. Available at http:/ / knowledge.wharton.upenn.edu/article/li-fungs-bruce-rockowitz-managing-supply-chains-in-a-flat-world/(accessed date July 7, 2015).

Lafontaine, F., M. Slade. 2012. Inter-firm contracts. R. Gibbons, J. Roberts, eds. The Handbook of Organizational Economics. Chapter 4. Princeton University Press, Princeton, New Jersey, 958-1013.

Lariviere, M. A., E. L. Porteus. 2001. Selling to the newsvendor: An analysis of price-only contracts. Manuf. Serv. Oper. Manag. 3 (4): 293-305.
Majumder, P., Srinivasan. 2008. Leadership and competition in network supply chains. Manage. Sci. 54 (6): 1189-1204.

Masson, R., L. Iosif, G. MacKerron, J. Fernie. 2007. Managing complexity in agile global fashion industry supply chains. Int. J. Log. Manag. 18 (2): 238-254.

Netessine, S., F. Zhang. 2005. Positive vs. negative externalities in inventory management: Implications for supply chain design. Manuf. Serv. Oper. Manag. 7 (1): 58-73.

Peng, M. W., A. S. York. 2001. Behind intermediary performance in export trade: Transactions, agents, and resources. J. Int. Bus. Stud. 32 (2): 327-346.

Perakis, G., G. Roels. 2007. The price of anarchy in supply chains: Quantifying the efficiency of price-only contracts. Manage. Sci. 53 (8): 1249-1268.

Purvis, L., M. Naim, D. Towill. 2013. Intermediation in agile global fashion supply chains. Int. J. Eng. Sci. Technol. 5 (2): 38- 48.

Rauch, J. 2001. Business and social networks in international trade. J. Econ. Lit. 39 (4): 1177-1203.

Rubinstein, A., A. Wolinsky. 1987. Middlemen. Q. J. Econ. 102 (3): 581.

Singh, N., X. Vives. 1984. Price and quantity competition in a differentiated duopoly. Rand J. Econ. 15 (4): 546-554.

$\mathrm{Wu}, \mathrm{S}$. D. 2004. Supply chain intermediation: a bargaining theoretic framework. D. Simchi-Levi, S. D. Wu, Z. M. Shen, eds. Handbook of Quantitative Supply Chain Analysis: Modelling in the E-Business Era. Kluwer Academic Publishers, Amsterdam, 67115.

Zhao, J. 2013. The Chinese Fashion Industry: An Ethnographic Approach. Bloomsbury Academic, London, UK.

\section{Supporting Information}

Additional Supporting Information may be found in the online version of this article:

Data S1: Robustness Checks and Additional Analysis. 